\title{
Autonomic Nervous System Function in Newly Diagnosed Multiple Sclerosis: Association With Lipid Levels and Insulin Resistance
}

\author{
Miroslava HARDOŇOVÁ ${ }^{\mathbf{1}}$, Pavel ŠIARNIK ${ }^{1}$, Monika SIVÁKOVÁ ${ }^{\mathbf{~}}$, Bianka SUCHÁ ${ }^{\mathbf{1}}$, \\ Miroslav VLČEK ${ }^{2}$, Richard IMRICH ${ }^{2}$, Peter TURČÁNI ${ }^{1}$, Andrea HAVRANOVÁ ${ }^{2}$, \\ Žofia RÁDIKOVÁ ${ }^{2}$, Ingrid ŽITŇANOVÁ ${ }^{3}$, Zuzana DEAN ${ }^{4}$, Adela PENESOVÁ ${ }^{2}$, \\ Branislav KOLLÁR ${ }^{1}$
}

${ }^{1} 1^{\text {st }}$ Department of Neurology, Faculty of Medicine, Comenius University, Slovakia, ${ }^{2}$ Institute of Clinical and Translational Research, Biomedical Research Center, Slovak Academy of Sciences, Slovakia, ${ }^{3}$ Institute of Medical Chemistry, Biochemistry and Clinical Biochemistry, Faculty of Medicine, Comenius University, Bratislava, Slovakia, ${ }^{4}$ AGEL Hospital, Levice, Slovakia

Received April 3, 2021

Accepted August 26, 2021

Epub Ahead of Print October 30, 2021

\section{Summary}

Autonomic nervous system (ANS) disorders are common in multiple sclerosis (MS). Previous studies showed differences in insulin resistance (IR) and lipoprotein levels in MS subjects compared to controls. Lipolysis caused by increased sympathetic activity could be one of the possible linking mechanisms leading to dyslipidemia in MS. Our study aimed to evaluate ANS activity in the context of glucose and lipid metabolism in people with MS. We prospectively measured short-term heart rate variability (HRV), fasting lipoprotein concentrations, and calculated IR indices based on plasma glucose and insulin levels during oral glucose tolerance test (oGTT) in 32 patients with MS and 29 healthy controls matched for age, sex and body mass index in our study. There was no significant difference in HRV parameters and lipoprotein levels between MS and controls. A significant positive correlation was found between low/high-frequency power ratio $(\mathrm{LF} / \mathrm{HF})$ and triglycerides $(r=0.413, p=0.021)$ in MS subjects but not in controls. A significantly lower whole-body insulin sensitivity index ( ISI $_{\text {Mat }}$ ) was found in patients with MS compared to the control group (7.3 \pm 3.7 vs. $9.8 \pm 5.6, p=0.041)$. No significant correlations were found between $L F / H F$ and IR parameters. In MS subjects, the positive correlation of LF/HF with triglycerides could reflect the effects of sympathetic activity on lipolysis. Positive correlations of sympathetic activity with increased lipoprotein levels could rather reflect processes associated with immune system activation/inflammation, than processes involved in glucose homeostasis maintenance.

\section{Key words}

Multiple sclerosis - Autonomic nervous system • Autonomic dysfunction $\bullet$ Heart rate variability $\bullet$ Lipoproteins

\section{Corresponding author}

Pavel Šiarnik, $1^{\text {st }}$ Department of Neurology, Faculty of Medicine, Comenius University, Mickiewiczova 13, 81369 Bratislava, Slovakia. E-mail: palo.siarnik@gmail.com

\section{Introduction}

Multiple sclerosis (MS) is a chronic immunemediated and inflammatory disease, leading to demyelination and degeneration of the central nervous system (CNS). It mainly affects young adults of working age and is one of the most common causes of invalidity (Thompson et al. 2018). Autonomic nervous system (ANS) dysfunction is commonly seen in patients with MS and is characterized by bladder and gastrointestinal disturbances, sexual dysfunction, abnormalities in cardiovascular functions, and sudomotor disorders. Additionally, MS patients report significant fatigue. These symptoms may have a significant impact on patients' quality of life and should be explored as part of the routine examination (Vieira et al. 2015, Adamec and Habek 2013, Miglis and Muppidi 2018, Videira et al. 2016).

Autonomic dysfunction in MS patients is 
assumed to develop due to the impairment of several critical pathways of the autonomic nervous system, including the brain stem, spinal cord, hypothalamus, and cerebral cortex (Gibbons 2019). Demyelinating plaques may disrupt reflex pathways in the insular, cingulated, and ventromedial prefrontal cortices, central nucleus of the amygdala, paraventricular hypothalamus, and the medulla. In addition, the plaques may interfere with the descending autonomic nervous system pathways during their course in the brainstem or spinal cord (Kanjwal et al. 2010).

The role of the ANS and mainly the hypothalamus in energetic metabolism is well known (Seoane-Collazo et al. 2015). Autonomic dysfunction, especially hyperactivation of the sympathetic branch in combination with poor physical fitness, may be a mechanism associated with early dysregulation of glucose metabolism (Carnethon et al. 2003). Recent studies suggest that changes in lipoprotein profile and subclasses are preceded by insulin resistance and hyperinsulinemia in patients with newly diagnosed MS (Radikova et al. 2018). Impaired insulin sensitivity may be an underlying cause for catabolism and lipolysis (Anderson et al. 1991). The function of ANS can also influence lipolysis and lipoprotein metabolism (Bartness et al. 2010). Recent evidence points to an important role of the hypothalamus in triglyceride (TG) metabolism through innervations of liver, white adipose tissue (WAT), and brown adipose tissue (BAT) mainly via sympathetic branches of the ANS. Various neuronal populations, such as neuropeptide $\mathrm{Y}$-expressing neurons and melanocortin-expressing neurons, as well hormones (i.e., GLP-1, leptin, and insulin), modulate sympathetic outflow from the hypothalamus toward target organs and thereby affects peripheral TG metabolism (Geerling et al. 2014). Lipolysis caused by increased sympathetic activity could be one of the possible linking mechanisms leading to dyslipidemia in MS. We assumed that increased sympathetic activity in people with MS could be an underlying mechanism involved in catabolism induced by decreased insulin sensitivity and increased lipolysis. Therefore, we analyzed sympathetic/parasympathetic balance in the context of insulin sensitivity and plasma lipid concentrations.

\section{Material and methods}

We prospectively enrolled patients from the MS registry of the $1^{\text {st }}$ Department of Neurology, Comenius
University in Bratislava for our study. The inclusion criteria were defined as: patients with newly diagnosed MS after the first episode of symptoms, an EDSS [Expanded Disability Status Scale] score less than 3, age between 18 and 50 years. All patients met the 2010 McDonald's criteria for the diagnosis of MS (Polman et al. 2011). Participants with a history of cardiovascular disease, hypertension, diabetes mellitus (type I and II), thyroid disease, current smoking, hepatic or renal disease, malignancy, and acute or chronic infection, or any current medication were excluded from the study. The first MS episode was treated with the pulse, short-term glucocorticoid therapy using methylprednisolone (1000 mg per day intravenously for 3-5 days). The examinations took place before acute treatment or, if not possible, at least 8 weeks after the glucocorticoid therapy. At the time of examination, patients were in remission or without any immunomodulatory therapy. Healthy volunteers served as controls. They were matched with patients for age, sex, and body mass index. All individuals participating in our study signed informed consent. All procedures performed in this study were in accordance with the ethical standards of the National research committee and with the 1964 Helsinki declaration and its later amendments or comparable ethical standards. The study was approved by the Ethics Committee of the University Hospital in Bratislava as well as by the Ethics Committee of Bratislava Self-Governing Region, Bratislava Slovakia (No 110/2016, 00581/2017/HF).

The examination started at 08:00 AM. The subjects were asked to stay fasting for 12 hours and restrain from intense physical activity for 24 hours before the study. Bodyweight and height were measured. Thereafter, the cubital vein was cannulated, and subjects rested for 30 minutes in a comfortable chair to relieve acute stress from venepuncture. They were then placed in a supine position. Subjects remained in this position for 15 minutes. During the whole procedure continuous electrocardiogram and chest respiratory movements were recorded (PowerLab, ADInstruments Pty Ltd, Bella Vista, NSW, Australia). Heart rate variability (HRV) analysis (Chart HRV module, ADInstruments Pty Ltd) was performed on $5 \mathrm{~min}$ long parts of recordings. Following HRV parameters were calculated: total power (TP) in the range $0.00-0.40 \mathrm{~Hz}$, low-frequency power (LF) in the range $0.04-0.15 \mathrm{~Hz}$, high-frequency power (HF) in the range $0.15-0.40 \mathrm{~Hz}, \mathrm{LF} / \mathrm{HF}$ ratio, and LF and $\mathrm{HF}$ powers in normalized units (LFnu, HFnu). 
HF parameter reflects mainly respiratory sinus arrhythmia and is used as an index of cardiac vagal control, LF provides an estimation of cardiac sympathetic activity, LF/HF ratio is used as a marker of cardiac sympathovagal balance (Vlcek et al. 2008).

After HRV assessment, subjects underwent a classic oral glucose tolerance test (oGTT). They drank a solution containing $75 \mathrm{~g}$ of glucose in $150 \mathrm{ml}$ of water and the blood samples were taken at $0,15,30,45,60,90$, and 120 minutes. Blood samples were centrifuged at $4{ }^{\circ} \mathrm{C}$ and aliquots of sera and plasma were stored frozen at $-70{ }^{\circ} \mathrm{C}$ until assayed. Insulin sensitivity/resistance indices were calculated using fasting (Matthews et al. 1985) and oGTT-derived glucose and insulin concentrations (Cederholm and Wibell 1990, Matsuda and DeFronzo 1999) as used previously in MS patients (Penesova et al. 2015).

In fasting conditions, plasma glucose concentrations and fasting serum total cholesterol (TC), low-density lipoprotein (LDL), high-density lipoprotein (HDL), and triglyceride (TG) levels were determined by standard procedure with enzymatic kits (Roche Diagnostics, Lewes, UK) using an autoanalyzer (Siemens Healthcare Diagnostics Inc., Tarrytown, NY, USA). Plasma insulin levels were measured by ELISA kits (ALPCO Diagnostics, Salem, NH, USA). Lipoprotein subfraction analysis was performed using high-resolution polyacrylamide gel electrophoresis technique - Lipoprint system (Quantimetrix Corporation, Redondo Beach, CA, USA), which enabled to analyze the following lipoprotein subfractions profile: the very-low-density lipoprotein (VLDL) fraction, the intermediate-density lipoproteins (IDL) C, B, and A, the low-density lipoprotein (LDL) with subfractions 1 and 2 (large LDL) and subfractions 3 to 7 (small dense LDL - sdLDL), and the high-density lipoprotein (HDL) subfractions categorized into large (subfractions 1-3), intermediate (subfractions 4-7), and small HDL (subfractions 8-10), as previously described (Radikova et al. 2018). The hypertriglyceridemic waist phenotype was set. It was defined as a waist circumference of $\geq 85 \mathrm{~cm}$ and a triglyceride level of $\geq 1.5 \mathrm{mmol} / \mathrm{l}$ in women, and waist circumference of $\geq 90 \mathrm{~cm}$, and a triglyceride level of $\geq 2.0 \mathrm{mmol} / 1$ or more in men (Blackburn et al. 2008).

The statistical analyses were assessed with SPSS version 18 (SPSS Inc., Chicago, USA). Categorical variables were expressed as numbers (\%), continuous variables as means ( \pm standard deviation), or median (interquartile range [IQR], minimal-maximal values) according to the normality of their distribution. The chisquare test, Mann-Whitney U test, and Student t-test were used for group comparisons of variables between MS patients and controls. To determine the relationships between HRV, lipoprotein levels, and IR parameters, Spearman and Pearson correlation coefficients were used. All tests were 2-sided and values of $\mathrm{P}<0.05$ were considered statistically significant.

\section{Results}

The study population consisted of 32 MS subjects and 29 healthy controls matched for age, sex, and body mass index. Characteristics of the study groups are included in Table 1. There was no significant difference in HRV parameters and lipoprotein levels between MS patients and controls. In MS patients, compared to controls, significantly lower values of ISI $_{\text {Mat }}$ were found (7.3 \pm 3.7 vs. $9.8 \pm 5.6, p=0.041)$. Other parameters of insulin sensitivity and resistance $\left(\mathrm{IR}_{\mathrm{HOMA}}\right.$ and $\left.\mathrm{ISI}_{\mathrm{Ced}}\right)$ were comparable between groups.

The LF/HF ratio positively correlated with the value of triglycerides $(r=0.413, p=0.021)$ in MS patients, but not in the control group (Table 2). In both groups, we failed to find any significant correlations between $\mathrm{LF} / \mathrm{HF}$ and parameters of insulin sensitivity or resistance (ISI ${ }_{\text {Mat }}$, $\mathrm{IR}_{\text {HOMA }}, \mathrm{ISI}_{\mathrm{Ced}}$ ) (Table 3).

\section{Discussion}

The results of our study confirm the previous findings of decreased whole-body insulin sensitivity in patients with newly diagnosed MS compared to the controls (Penesova et al. 2015). We failed to find any significant differences between the groups in HRV parameters and lipoprotein levels. However, a significant positive correlation was found between LF/HF and triglycerides $(r=0.413, p=0.021)$ in MS subjects, but not in controls. On the other hand, no significant correlations of LF/HF with IR parameters were found.

In our current study, lipoprotein levels and ANS parameters were comparable between MS patients and healthy controls. The role of lipoprotein metabolism and ANS regulation in MS progression seems to be complex and possibly bidirectional. Some studies, in contrast with our study, revealed that MS patients had higher TG, LDL, and lower HDL than control subjects (Fahmi et al. 2020, Winstock-Guttman et al. 2011, Sicras-Mainar et al. 2017). However, when compared to our study with newly 
Table 1. Characteristics of the study population

\begin{tabular}{|c|c|c|c|}
\hline & MS & Control group & $\mathbf{P}$ \\
\hline$N$ & 32 & 29 & \\
\hline Age & $30.2 \pm 7.1$ & $29.8 \pm 6.7$ & 0.809 \\
\hline Women/men & $19 / 13(59.4 / 40.6 \%)$ & $17 / 12(58.6 / 41.4 \%)$ & 0.952 \\
\hline Body mass index $\left(\mathrm{kg} / \mathrm{m}^{2}\right)$ & $23.1 \pm 4.2$ & $23.9 \pm 4.7$ & 0.479 \\
\hline Waist circumference $(\mathrm{cm})$ & $83.1 \pm 10.5$ & $83.5 \pm 12.5$ & 0.894 \\
\hline$T P(m s)$ & $2988.1(3553.3 ; 755.4-14521.8)$ & $3232.3(5857.2 ; 448.2-14491.9)$ & 0.394 \\
\hline$L F(n u)$ at rest & $55.0 \pm 18.2$ & $52.4 \pm 17.4$ & 0.572 \\
\hline HF (nu) at rest & $40.5 \pm 17.3$ & $43.4 \pm 16.5$ & 0.513 \\
\hline$L F / H F$ at rest & $1.4(1.8 ; 0.3-5.1)$ & $1.3(1.1 ; 0.2-5.4)$ & 0.593 \\
\hline Fasting glucose (mmol/l) & $5.0 \pm 0.4$ & $4.8 \pm 0.4$ & 0.054 \\
\hline Glucose at $120 \mathrm{~min}$. of oGTT (mmol/l) & $6.5 \pm 1.7$ & $6.0 \pm 1.7$ & 0.208 \\
\hline Fasting insuline $(\mathrm{mIU} / \mathrm{l})$ & $4.5(2.4 ; 1.8-24.6)$ & $4.7(5.4 ; 1.1-10.1)$ & 0.554 \\
\hline Insulin at $120 \mathrm{~min}$. of oGTT (mIU/l) & $42.8(44.2 ; 12.8-150.6)$ & $31.9(24.9 ; 4.9-92.2)$ & $0.029 *$ \\
\hline$I S I_{\text {Mat }}$ & $7.3 \pm 3.7$ & $9.8 \pm 5.6$ & $0.041 *$ \\
\hline$I S I_{C e d}$ & $55.6 \pm 15.7$ & $63.4 \pm 17.1$ & 0.068 \\
\hline$I R_{H O M A}$ & $1.0(0.6 ; 0.4-5.9)$ & $1.0(1.1 ; 0.2-2.2)$ & 0.419 \\
\hline Total cholesterol (mmol/l) & $4.3 \pm 0.8$ & $4.1 \pm 0.7$ & 0.253 \\
\hline Hypercholesterolemia (>5 mmol/l) & $6(18.8 \%)$ & $2(6.9 \%)$ & 0.171 \\
\hline Triglycerides $(\mathrm{mmol} / \mathrm{l})$ & $0.8 \pm 0.4$ & $0.9 \pm 0.6$ & 0.409 \\
\hline Hypertriglyceridemia (>1.7 mmol/l) & $1(3.1 \%)$ & $3(10.3 \%)$ & 0.255 \\
\hline Hypertriglyceridemic waist phenotype & $2(6.3 \%)$ & $2(6.9 \%)$ & 0.919 \\
\hline LDL cholesterol (mmol/l) & $2.6 \pm 0.7$ & $2.5 \pm 0.6$ & 0.532 \\
\hline$L D L 1-2(m g / d l)$ & $27.0(37.0 ; 0-70.0)$ & $34.0(30.0 ; 0-69.0)$ & 0.641 \\
\hline$L D L 3-7(m g / d l)$ & $0(2.0 ; 0-27.0)$ & $0(2.0 ; 0-28.0)$ & 0.906 \\
\hline HDL cholesterol (mmol/l) & $1.4 \pm 0.3$ & $1.4 \pm 0.4$ & 0.751 \\
\hline Large HDL $(\mathrm{mg} / \mathrm{dl})$ & $21.0(15.0 ; 7.0-81.0)$ & $21.0(20.5 ; 8.0-45.0)$ & 0.900 \\
\hline Medium HDL $(m g / d l)$ & $24.7 \pm 5.2$ & $24.1 \pm 5.3$ & 0.676 \\
\hline Small HDL $(m g / d l)$ & $4.0(3.0 ; 0-12.0)$ & $5.0(4.0 ; 0-10.0)$ & 0.340 \\
\hline$V L D L(m g / d l)$ & $25.8 \pm 8.4$ & $25.8 \pm 7.1$ & 0.982 \\
\hline$I D L(m g / d l)$ & $50.0 \pm 19.2$ & $43.7 \pm 13.3$ & 0.149 \\
\hline
\end{tabular}

The values in the table are given as number $(\%)$, mean \pm standard deviation or median, interquartile range, range. TP: total power in

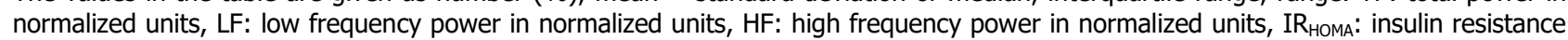
index, ISI $_{\text {Mat }}$ : whole body insulin sensitivity index, ISI $_{\text {Ced: }}$ peripheral insulin sensitivity index, VLDL: very low-density lipoprotein, IDL: intermediate-density lipoprotein, LDL: low-density lipoprotein, HDL: high-density lipoprotein

diagnosed MS, all of these studies included subjects with longer disease duration (average duration $>4$ years) and multiple subjects in these studies received diseasemodifying therapy. Autonomic dysfunction is common in MS and it is supposed that sympathetic dysfunction may contribute to the enhancement of inflammatory and neurodegenerative pathways underlying MS progression (Racosta et al. 2016). Autonomic dysfunction and a significant increase of sympathetic activity during the early stages of MS have been described previously. However, data from newly diagnosed subjects without any disease-modifying therapy are rare (Racosta et al.
2016, Findling et al. 2020). In the current study, we found no significant differences in HRV parameters between MS subjects and controls. This finding suggests no significant sympathetic nervous system overactivation or autonomic dysfunction in newly diagnosed MS subjects. This could be explained by only a subtle impairment of critical autonomic nervous system pathways by demyelinating plaques in the early stages of MS. Previously, it was demonstrated that longer MS duration led to progressive impairment of cardiac autonomic balance assessed by HRV (Mahovic et al. 2007). 
Table 2. Correlations of LF/HF and lipoprotein levels

\begin{tabular}{lcccc}
\hline & \multicolumn{2}{c}{ MS } & $\mathbf{2}$ Control group \\
& $\mathbf{r}$ & $\mathbf{p}$ & $\mathbf{r}$ & $\mathbf{P}$ \\
\hline Total cholesterol & 0.328 & 0.072 & -0.189 & 0.327 \\
Triglycerides & 0.413 & $0.021^{*}$ & 0.034 & 0.859 \\
LDL & 0.233 & 0.206 & -0.189 & 0.327 \\
LDL1-2 & 0.214 & 0.256 & -0.028 & 0.886 \\
LDL3-7 & 0.158 & 0.405 & -0.115 & 0.553 \\
HDL & 0.063 & 0.736 & 0.124 & 0.520 \\
Large HDL & 0.091 & 0.632 & -0.140 & 0.468 \\
Intermediate HDL & -0.015 & 0.937 & 0.066 & 0.733 \\
Small HDL & -0.010 & 0.958 & 0.316 & 0.095 \\
VLDL & 0.286 & 0.125 & -0.095 & 0.623 \\
IDL & 0.029 & 0.880 & -0.066 & 0.733 \\
\hline
\end{tabular}

VLDL: very low-density lipoprotein, IDL: intermediate-density lipoprotein, LDL: low-density lipoprotein, HDL: high-density lipoprotein

Table 3: Correlations of LF/HF at rest with IR parameters

\begin{tabular}{lccccc}
\hline & & MS & & \multicolumn{2}{c}{ Control group } \\
& $\mathbf{r}$ & $\mathbf{p}$ & $\mathbf{~ r ~}$ & $\mathbf{p}$ \\
\hline$I R_{\text {HOMA }}$ & 0.044 & 0.816 & 0.311 & 0.101 \\
$I S I_{\text {Mat }}$ & -0.076 & & 0.684 & -0.290 & 0.127 \\
$I S I_{\text {Ced }}$ & -0.208 & & 0.262 & -0.221 & 0.249 \\
\hline
\end{tabular}

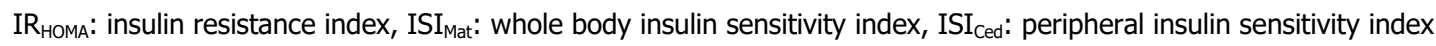

It is known, that sympathetic nervous system activation is an important mechanism involved in lipolysis (Bartness et al. 2014). However, there are spare and conflicting data regarding the aspects of dyslipidemia in the MS population and the role of ANS in this process remains unknown (Radikova et al. 2018, Noori et al. 2019, Giubilei et al. 2002, Zhornitsky et al. 2016). Autonomic dysfunction, especially sympathetic activation, could be also a mechanism associated with early dysregulation of glucose metabolism (Carnethon et al. 2003).

Results of the current study do not support our initial assumption that decreased insulin sensitivity could lead to increased sympathetic activity and subsequent lipolysis in newly diagnosed MS subjects. Consistently with previous studies, we found significantly reduced insulin sensitivity (determined as the ISI $\mathrm{Iat}_{\text {at }}$ index) in MS subjects (Penesova et al. 2015, Ruiz-Agülles et al. 2018). Reduced insulin sensitivity in our newly diagnosed MS patients suggests impaired glucose metabolism already at an early stage of the disease, which can gradually unmask with a longer duration of the disease. In our recent study, we assumed that insulin resistance could precede changes in the lipid profile in the early stage of MS (Radikova et al. 2018). We suppose that impairment of glucose metabolism in newly diagnosed MS, which was observed also in this study, could be too subtle and early to induce catabolism and subsequent lipolysis (Andreson et al. 1991). We failed to find any associations of IR parameters with increased sympathetic activity (represented by LF/HF), that belongs to the typical processes involved in glucose homeostasis maintenance (Wehrwein et al. 2016).

In the group of MS, in contrast to the control group, we found significant positive correlations between the LF/HF and the levels of triglycerides. This finding could suggest an association of sympathetic activity with higher triglyceride levels in patients with MS, but the study is not designed to prove any causality in this relationship. We speculate that this may be considered as the first sign of changes in lipoprotein subclasses in relation to early changes in sympathetic system activity in newly diagnosed MS patients. It is necessary to admit that only a longer follow-up of the patients could indicate 
if changes in ANS and lipoprotein profile become more prominent with time in the MS patients when compared to the controls.

However, our findings could suggest that increased sympathetic activity does not belong to the key mechanisms linking an impaired insulin sensitivity with dyslipidemia in MS subjects. No significant correlations of $\mathrm{LF} / \mathrm{HF}$ with IR parameters were found. We suppose that positive correlations of sympathetic activity with increased lipoprotein levels could rather reflect processes associated with activation of immune system/inflammation, than processes involved in glucose homeostasis maintenance. Similar associations were described in autoimmune inflammatory diseases including rheumatoid arthritis or systemic lupus erythematosus (Szabó et al. 2017, Kerekes et al. 2014). Future prospective studies could help to elucidate this association.

We have to admit that a small sample size is the main limitation of our study. Longer follow-up of our group is also warranted to elucidate trends in ANS and lipoprotein levels change. On the other hand, the findings of our study were not confounded by any use of diseasemodifying treatment, and all subjects were considered as "apparently healthy". The design of our study limits the reliability of the results. Enrollment of a specific population with newly diagnosed MS does not allow deeper analysis of metabolic changes accompanying MS. To increase the reliability of the current results, future studies should include also subgroup with a longer history of the disease.

\section{Abbreviations}

ANS, autonomic nervous system; BAT, brown adipose tissue (BAT); CNS, central nervous system; EDSS, Expanded Disability Status Scale; HDL, high density lipoprotein; HF, high frequency; HRV, heart rate variability; IDL, intermediate-density lipoprotein; IR, insulin resistence; $\mathrm{ISI}_{\text {Mat }}$, whole-body insulin sensitivity index; LDL, lowdensity lipoprotein; LF, low frequency power; MS, multiple sclerosis; oGTT, oral glucose tolerance test; TC, total cholesterol; TG, triglyceride; VLDL, very low-density lipoprotein; WAT, white adipose tissue

\section{Conflict of Interest}

There is no conflict of interest.

\section{Acknowledgements}

We express our appreciation to the patients and healthy volunteers who participated in the study. This study was supported by the APVV-15-0228 grant, VEGA 2/0129/20 grant, MZ SR 2018/37-LFUK-11 grant, and by The Framework Programme for Research and Technology Development, Project: Building of Centre of Excellency for Sudden Cerebral Vascular Events, Comenius University Faculty of Medicine in Bratislava (ITMS:26240120023), co-financed by European Regional Development Fund.

\section{Authors' Contributions}

AP, BK, RI, PS and PT have participated in study conception and design, MS, ZR, MV, RI, AH, and AP have been responsible for acquisition of data, analysis and interpretation of data, MS, MH, PS and BK have been involved in drafting the paper, AP, MV, IZ, BS, ZD and $\mathrm{ZR}$ revised the final draft of manuscript for important intellectual content. All authors read and approved the manuscript.

\section{References}

ADAMEC I, HABEK M: Autonomic dysfunction in multiple sclerosis. Clin Neurol Neurosurg 115 Suppl 1: S73-S78, 2013. https://doi:10.1016/j.clineuro.2013.09.026

ANDERSON EA, HOFFMAN RP, BALON TW, SINKEY CA, MARK AL: Hyperinsulinemia produces both sympathetic neural activation and vasodilation in normal humans. J Clin Invest 87: 2246-2252, 1991. https://doi:10.1172/JCI115260

BARTNESS T J, LIU Y, SHRESTA YB, RYU V: Neural innervation of white adipose tissue and the control of lipolysis. Front Neuroendocrinol 35: 473-493, 2014. https://doi:10.1016/j.yfrne.2014.04.001

BARTNESS T J, SHRESTHA YB, VAUGHAN CH, SCHWARTZ GJ, SONG CK: Sensory and sympathetic nervous system control of white adipose tissue lipolysis. Mol Cell Endocrinol 318: 34-43, 2010. https://doi:10.1016/j.mce.2009.08.031 
BLACKBURN P, LEMIEUX I, LAMARCHE B: Type 2 diabetes without the atherogenic metabolic triad does not predict angiographically assessed coronary artery disease in women. Diabetes Care 31: 170-172, 2008. https://doi:10.2337/dc07-0272

CARNETHON M R, JACOBS DR Jr, SIDNEY S, LIU K: Influence of autonomic nervous system dysfunction on the development of type 2 diabetes: the CARDIA study. Diabetes Care 26: 3035-3041, 2003. https://doi:10.2337/diacare.26.11.3035

CEDERHOLM J, WIBELL L: Insulin release and peripheral sensitivity at the oral glucose tolerance test. Diabetes Res Clin Pract 10: 167-175, 1990. https://doi:10.1016/0168-8227(90)90040-Z

FAHMI RM, El EBEARY M, ALRASHEED AM, ELKHATIB THM: Metabolic syndrome components and disease disability in egyptian multiple sclerosis patients. Mult Scler Relat Disord 44: 102336, 2020. https://doi:10.1016/j.msard.2020.102336

FINDLING O, HAUER L, PEZAWAS T, ROMMER PS, STRUHAL W, SELLNER J: Cardiac autonomic dysfunction in multiple sclerosis: a systematic review of current knowledge and impact of immunotherapies. J Clin Med 9, 2020. https://doi:10.3390/jcm9020335

GEERLING JJ, BOON MR, KOOIJMAN S, PARLEVLIET ET, HAVEKES LM, ROMIJN JA, MEURUS IM, RENSEN PC: Sympathetic nervous system control of triglyceride metabolism: novel concepts derived from recent studies. J Lipid Res 55: 180-189, 2014. https://doi:10.1194/j1r.R045013

GIBBSONS CH: Basics of autonomic nervous system function. Handb Clin Neurol 160: 407-18, 2019. https://doi:10.1016/B978-0-444-64032-1.00027-8

GIUBILEI F, ANTONINI G, Di LEGGE S, SORMANI MP, PANTANO P, ANTONINI R, SEPE-MONTI M, CARAMIA F, POZZILLI C: Blood cholesterol and MRI activity in first clinical episode suggestive of multiple sclerosis. Acta Neurol Scand 106: 109-112, 2002. https://doi:10.1034/j.1600-0404.2002.01334.X

KANJWAL K, KARABIN B, KANJWAL Y, GRUBB BP: Autonomic dysfunction presenting as postural orthostatic tachycardia syndrome in patients with multiple sclerosis. Int J Med Sci 7: 62-67, 2010. https://doi:10.7150/ijms.7.62

KEREKES G, NURMOHAMED MT, GONZÁLES-GAY MA, SERES I, PARAGH G, KARDOS Z, BARÁTH Z, TAMÁSI L, SOLTÉSZ P, SZEKANECZ Z: Rheumatoid arthritis and metabolic syndrome. Nat Rev Rheumatol 10: 691-696, 2014. https://doi:10.1038/nrrheum.2014.121

MAHOVIC D, LAKUSIC N: Progressive impairment of automonic control of heart rate in patients with multiple sclerosis. Arch Med Res 38: 322-325, 2007. https://doi:10.1016/j.arcmed.2006.11.009

MATSUDA M, DE FRONZO RA: Insulin sensitivity indices obtained from oral glucose tolerance testing: comparison with the euglycemic insulin clamp. Diabetes Care 22: 1462-1470, 1999. https://doi:10.2337/diacare.22.9.1462

MATTHEWS DR, HOSKER JP, RUDENSKI AS, NAYLOR BA, TREACHER DF, TURNER RC: Homeostasis model assessment: insulin resistance and beta-cell function from fasting plasma glucose and insulin concentrations in man. Diabetologia 28: 412-419, 1985. https://doi:10.1007/BF00280883

MIGLIS MG, MUPPIDI S: Autonomic dysfunction in multiple sclerosis and other updates on recent autonomic research. Clin Auton Res 28: 391-393, 2018. https://doi:10.1007/s10286-018-0548-5

NOORI H, GHEINI MR, REZAEIMANESH N, SAEEDI R, REZAEI ALIBADI H, SAHRAIAN MA, NASER MOGHADASI A: The correlation between dyslipidemia and cognitive impairment in multiple sclerosis patients. Mult Scler Relat Disord 36: 101415, 2019. https://doi:10.1016/j.msard.2019.101415

PENESOVA A, VLCEK M, IMRICH R, VERNEROVA L, MARKO A, MESKOVA M, GRUNNEROVA L, TURCANI P, JEZOVA D, KOLLAR B: Hyperinsulinemia in newly diagnosed patients with multiple sclerosis. Metab Brain Dis 30: 895-901, 2015. https://doi:10.1007/s11011-015-9665-1

POLMAN CH, REINGOLD SC, BANWELL B, CLANET M, COHEN JA, FILIPPI M, FUJIHARA K, HAVRDOVA E, HUTCHINSON M, KAPPOS L, LUBLIN FD, MONTALBAN X, O'CONNOR P, SANBERGWOLLHEIM M, THOMPSON AJ, WAUBANT E, WEINSHENKER B, WOLINSKY JS: Diagnostic criteria for multiple sclerosis: 2010 revisions to the McDonald criteria. Ann Neurol 69: 292-302, 2011. https://doi:10.1002/ana.22366

RACOSTA JM, KIMPINSKI K: Autonomic dysfunction, immune regulation, and multiple sclerosis. Clin Auton Res 26: 23-31, 2016. https://doi:10.1007/s10286-015-0325-7 
RADIKOVA Z, PENESOVA A, VLCEK M, HAVRANOVA A, SIVAKOVA M, SIARNIK P, ZITNANOVA I, IMRICH R, KOLLAR B, TURCANI P: LDL and HDL lipoprotein subfractions in multiple sclerosis patients with decreased insulin sensitivity. Endocr Regul 52: 139-45, 2018. https://doi:10.2478/enr-2018-0017

RUIZ-ARGÜELLES A, MÉNDEZ-HUERTA MA, LOZANO CD, RUIZ-ARGÜELLES GJ: Metabolomic profile of insulin resistance in patients with multiple sclerosis is associated to the severity of the disease. Mult Scler Relat Disord 25: 316-321, 2018. https://doi:10.1016/j.msard.2018.08.014

SEOANE-COLLAZO P, FERNǿ P, GONZALES F, DIÉGUEZ C, LEIS R, NOGUEIRAS R, LÓPEZ M: Hypothalamic-autonomic control of energy homeostasis. Endocrine 50: 276-291, 2015. https://doi:10.1007/s12020-015-0658-y

SICRAS-MAINAR A, EUÍZ-BEATO E, NAVARRO-ARTIEDA R, MAURINO J: Comorbidity and metabolic syndrome in patients with multiple sclerosis from Asturias and Catalonia, Spain. BMC Neurol 17: 134, 2017. https://doi:10.1186/s12883-017-0914-2

SZABÓ MZ, SZODORAY P, KISS E: Dyslipidemia in systemic lupus erythematosus. Immunol Res 65: 543-550, 2017. https://doi:10.1007/s12026-016-8892-9

THOMPSON AJ, BARANZINI SE, GEURTS J, HEMMER B, CICCARELLI O: Multiple sclerosis. Lancet 391: 1622-1636, 2018. https://doi:10.1016/S0140-6736(18)30481-1

VIDEIRA G, CASTRO P, VIEIRA B, FILIPE JP, SANTOS R, AZEVEDO E, SÁ MJ, ABREU P: Autonomic dysfunction in multiple sclerosis is better detected by heart rate variability and is not correlated with central autonomic network damage. J Neurol Sci 367: 133-137, 2016. https://doi:10.1016/j.jns.2016.05.049

VIEIRA B, COSTA A, VIDEIRA G, SÁ MJ, ABREU P: Prevalence of autonomic dysfunction in patients with multiple sclerosis. Acta Med Port 28: 51-55, 2015. https://doi:10.20344/amp.5562

VLCEK M, RADIKOVA Z, PENESOVA A, KVETNANSKY R, IMRICH R: Heart rate variability and catecholamines during hypoglycemia and orthostasis. Auton Neurosci 143: 53-57, 2008. https://doi:10.1016/j.autneu.2008.08.001

WEHRWEIN EA, ORER HS, BARMAN SM: Overview of the anatomy, physiology, and pharmacology of the autonomic nervous system. Compr Physiol 6: 1239-1278, 2016. https://doi:10.1002/cphy.c150037

WEINSTOCK-GUTTMAN B, ZIVADINOV R, MAHFOOZ N: Serum lipid profiles are associated with disability and MRI outcomes in multiple sclerosis. J Neuroinflammation 8: 127, 2011. https://doi:10.1186/1742-2094-8-127

ZHORNITSKY S, MCKAY KA, METZ LM, TEUNISSEN CE, RANGACHARI M: Cholesterol and markers of cholesterol turnover in multiple sclerosis: relationship with disease outcomes. Mult Scler Relat Disord 5: 53-65, 2016. https://doi:10.1016/j.msard.2015.10.005 